\title{
Use of parenteral glucocorticoids and the risk of new onset type 2 diabetes mellitus: A case-control study
}

Citation for published version (APA):

Keyany, A., Nielen, J. T. H., Souverein, P. C., de Vries, F., \& van den Bemt, B. (2018). Use of parenteral glucocorticoids and the risk of new onset type 2 diabetes mellitus: A case-control study. Diabetes Research and Clinical Practice, 139, 100-106. https://doi.org/10.1016/j.diabres.2018.02.010

Document status and date:

Published: 01/05/2018

DOI:

10.1016/j.diabres.2018.02.010

Document Version:

Publisher's PDF, also known as Version of record

Document license:

Taverne

Please check the document version of this publication:

- A submitted manuscript is the version of the article upon submission and before peer-review. There can be important differences between the submitted version and the official published version of record.

People interested in the research are advised to contact the author for the final version of the publication, or visit the DOI to the publisher's website.

- The final author version and the galley proof are versions of the publication after peer review.

- The final published version features the final layout of the paper including the volume, issue and page numbers.

Link to publication

\footnotetext{
General rights Owners
rights.

- You may freely distribute the URL identifying the publication in the public portal. please follow below link for the End User Agreement:

www.umlib.nl/taverne-license

Take down policy

If you believe that this document breaches copyright please contact us at:

repository@maastrichtuniversity.nl

providing details and we will investigate your claim.
}

Copyright and moral rights for the publications made accessible in the public portal are retained by the authors and/or other copyright owners and it is a condition of accessing publications that users recognise and abide by the legal requirements associated with these

- Users may download and print one copy of any publication from the public portal for the purpose of private study or research.

- You may not further distribute the material or use it for any profit-making activity or commercial gain

If the publication is distributed under the terms of Article $25 \mathrm{fa}$ of the Dutch Copyright Act, indicated by the "Taverne" license above, 


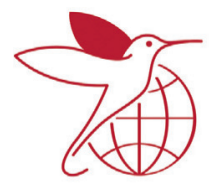

International

Diabetes

Federation

\title{
Use of parenteral glucocorticoids and the risk of new onset type 2 diabetes mellitus: A case-control study
}

\author{
Ala Keyany ${ }^{a}$, Johannes T.H. Nielen ${ }^{b, c}$, Patrick C. Souverein ${ }^{b}$, Frank de Vries ${ }^{b, c, d, *}$, \\ Bart van den Bemt ${ }^{a, e}$ \\ ${ }^{a}$ Department of Pharmacy, Sint Maartenskliniek, Nijmegen, The Netherlands \\ ${ }^{\mathrm{b}}$ Division of Pharmacoepidemiology and Clinical Pharmacology, Utrecht Institute of Pharmaceutical Sciences, Utrecht University, Utrecht, \\ Netherlands \\ ${ }^{\mathrm{c}}$ Department of Epidemiology, Care and Public Health Research Institute (CAPHRI), Maastricht University, Maastricht, the Netherlands \\ ${ }^{\mathrm{d}}$ Department of Clinical Pharmacy and Toxicology, Maastricht University Medical Centre+, Maastricht, Netherlands \\ ${ }^{e}$ Department of Pharmacy, Radboud University Medical Center, Nijmegen, The Netherlands
}

\section{A R T I C L E I N F O}

\section{Article history:}

Received 18 September 2017

Received in revised form

3 January 2018

Accepted 6 February 2018

Available online 21 March 2018

Keywords:

Corticosteroids

Type 2 diabetes mellitus

Parenteral corticosteroids

Gluco-corticosteroids

Pharmacoepidemiology

\begin{abstract}
A B S T R A C T
Background: Use of oral glucocorticoids (GCs) has been associated with hyperglycaemia and type 2 diabetes mellitus (T2DM). However, unlike oral GCs, there is minimal or no data on the effect of parenteral GC use on T2DM.

Objective: To assess the association between use of parenteral GCs and the risk of receiving a first prescription of a non-insulin antidiabetic drug (NIAD) as a proxy for new onset of T2DM.

Methods: A population based case-control study was performed using the Clinical Practice Research Datalink (CPRD). Cases $(n=177,154)$ were defined as patients $>18$ years of age who had their first ever NIAD prescription between January 1987 and October 2013. Controls were matched by age, gender and general practitioner practice. Conditional logistic regression analyses were used to estimate the risk of NIAD prescription and use of parenteral GCs. Our analyses were statistically adjusted for lifestyle factors, comorbidities and concomitant drug use.

Results: Although this study confirmed that oral GCs increases the risk of receiving a first prescription of a NIAD (OR 2.63 [95\% CI 2.53-2.73]), there was no association between the use of parenterally administered GCs and the risk of receiving a first prescription of a NIAD (OR 0.88 [95\% CI 0.76-1.02]). The number of GC prescriptions was not associated with risk of new onset T2DM compared to no parenteral GCs use; neither the type of GC.

Conclusion: Our study does not demonstrate an association between the use of parenteral GCs and the risk of new onset of T2DM.
\end{abstract}

(c) 2018 Elsevier B.V. All rights reserved.

\footnotetext{
* Corresponding author at: Division of Pharmacoepidemiology and Clinical Pharmacology, Utrecht Institute for Pharmaceutical Sciences, Utrecht University, The Netherlands.

E-mail address: f.devries@uu.nl (F. de Vries).

https://doi.org/10.1016/j.diabres.2018.02.010

0168-8227/@ 2018 Elsevier B.V. All rights reserved.
} 


\section{Introduction}

Glucocorticoids (GCs) are widely used as treatment for many diseases because of their anti-inflammatory and immunosuppressive properties. Despite their efficacy, their use has been associated with various side effects, including hyperglycaemia and induction of type 2 diabetes mellitus (T2DM) [1-7].

The risk of developing GC-induced diabetes has previously been described in multiple observational studies. A casecontrol study demonstrated that orally administered GCs may be associated with up to $2 \%$ of incident cases of diabetes in a primary care population [1]. Two other observational studies showed a two-fold increased risk of T2DM with oral GC use $[6,3]$. The main determinants of developing diabetes are the daily dose of GCs, type of GC, a longer duration of treatment, continuous use, an older age, a higher glycosylated haemoglobin (HbA1c) level at baseline, a higher Body Mass Index (BMI), family history of diabetes or race $[5,7,8]$.

Multiple mechanisms have been suggested to be involved in the development of GC-induced T2DM, such as increased hepatic glucose production, inhibition of glucose uptake in muscles and adipose tissue, and decreased beta-cell function [7]. GCs can induce diabetogenic side effects through interactions with the regulation of glucose homeostasis. Under conditions of excess and/or long-term treatment, GCs can induce peripheral insulin resistance by impairing insulin signalling, which results in reduced glucose in the cells and elevated endogenous glucose production. Furthermore, GCs can promote abdominal obesity, elevate plasma fatty acids and triglycerides. In response to GC-induced peripheral insulin resistance and in an attempt to maintain normoglycaemia, pancreatic $\beta$-cells undergo several adaptations which results in hyperinsulinaemia. Failure of $\beta$-cells to compensate for this situation favours glucose homeostasis disruption, which can result in hyperglycaemia $[9,10]$.

Similar to oral GCs, parenteral GCs are used mainly as pulse therapy in patients with rheumatoid arthritis and in patients with osteoarthritis. In a previous study, $50 \%$ of patients with osteoarthritis who underwent a knee or hip replacement surgery had received parenteral GCs in the 2years prior to surgery [11]. Previous studies have also demonstrated that the use of parenteral GCs is associated with hyperglycaemia in patients with diabetes and in patients without diabets. Intravenous administration of high dose (1 g) methylprednisolone for a period of three days in nondiabetic patients resulted in significant increase of fasting glucose levels [12]. Administration of methylprednisolone acetate at the knee joint in well controlled diabetic patients showed a significant increase in blood glucose levels with peak values seen between 2 and $24 \mathrm{~h}$ following the injection. This increase usually lasted between 2 and 5 days $[13,14]$. Furthermore, elevated glucose levels were seen in both diabetic and non-diabetic patients after injection of three $5.625 \mathrm{mg}$ cortivazole injections ( $85 \mathrm{mg}$ prednisolone-equivalent) at the shoulder joint at 3-day interval. No significant effect on cholesterol or triglyceride levels have been found [15].
However, unlike oral GCs, there is minimal or no data regarding the incidence of new onset of T2DM among parenteral GC users. Due to the different routes of administration and different dose regimes, the risk of T2DM may differ from oral GCs. Therefore, the objective of this study was to assess the association between use of parenteral GCs and the risk of receiving a first prescription of a non-insulin antidiabetic drug (NIAD) as a proxy for new onset T2DM.

\section{Methods}

\subsection{Data sources}

A case-control study was performed using the Clinical Practice Research Datalink (CPRD). The CPRD is a large primary care database containing medical records registered by over 674 general practitioners (GP) in the UK. It represents $6.9 \%$ of the total British population. In the UK, GPs play a key role in the healthcare system as they are responsible for primary care and specialist referrals. Consequently, this database provides information on a wide range of medical records, including diagnoses, prescriptions, specialist referrals, and laboratory test results [16]. The study protocol was approved by the Independent Scientific Advisory Committee (ISAC), protocol number: 16_091R.

\subsection{Study population}

All patients (males and females aged $>18$ years), between January 1987 and October 2013, who had their first ever prescription record of a NIAD were defined as a case. The first prescription record of a NIAD was used as a proxy for new onset of T2DM. NIADs included metformin, sulphonylurea, Glucagon-like peptide-1 (GLP-1) analogues, Dipeptidyl peptidase-4 (DPP-4) inhibitors, meglitinides, thiazolidinediones, and acarbose. The index date was defined as the date of the first NIAD prescription. A minimum period of 12 months of follow-up before the index date was required to ensure that we were dealing with new onset of T2DM. For each T2DM patient, one control patient without a NIAD or insulin prescription prior to the index date was selected and matched by year of birth, sex, and GP practice using incidence density sampling.

\subsection{Exposure assessment}

Use of oral and parenteral (intraarticular/intrabursal/periarti cular/intramuscular/intradermal) GCs was determined by reviewing prescriptions before the index date (Supplementary Table 1 and Supplementary Table 2). Current users comprised all patients with at least one recorded prescription within the 90-day period before index date. Recent users were those who received a GC between 91 days and 180 days before index date, but without a prescription in the 90-day period before index date. Past users were defined as patients who had a last GC prescription more than 180 days before the index date. 


\subsection{Covariates}

We reviewed the literature to identify risk factors for T2DM. Risk factors including BMI (most recent prior to index date) and smoking status were used as potential confounders. Furthermore, a history of comorbidities such as heart failure, angina pectoris, acute myocardial infarction (AMI), hypertension, hypercholesterolemia, arrhythmia, cerebrovascular, osteoarthritis, systemic lupus erythematosus, rheumatoid arthritis, transplantation, retinopathy and neuropathy ever before index date were also included. Drugs which may induce hyperglycaemia [17], such as loop diuretics, betablockers, antipsychotics, protease inhibitor, other GC drugs (oral, nasal, dermal, etc.) and other drugs such as calcium channel blockers, RAAS inhibitors, statins in the six months prior to index date were also considered as potential confounders.

\subsection{Statistical analysis}

Conditional logistic regression analyses (using SAS version 9.3, PHREG procedure) were used to assess the association between new onset of T2DM and use of oral and parenteral (intraarticular/intrabursal/periarticular/intramuscular/intra dermal) GCs, expressed as odds ratios (OR) with corresponding $95 \%$ confidence intervals (CI). In all analyses, covariates were included as confounders if they independently changed the beta-coefficient for current GC exposure by at least 5\%, or when consensus about inclusion existed within the team of researchers, supported by clinical evidence from literature. To determine whether a duration-response relationship was present we stratified the current oral and parenteral GC users by number of prescriptions ever before index date $(1-4,5-8,>8$ prescriptions). To determine whether there is a difference between the various parenteral GCs, current users were be stratified by type of parenteral GC (triamcinolone, prednisolone, methylprednisolone, hydrocortisone, dexamethasone).

\section{Results}

Between January 1987 and October 2013, 177,154 cases and 177,154 controls were identified. The characteristics of cases and controls are summarized in Table 1. Age, gender and smoking status distribution were similar among cases and controls. Cases had a higher average BMI $\left(31.4 \mathrm{~kg} / \mathrm{m}^{2}\right.$ [cases] vs $26.5 \mathrm{~kg} / \mathrm{m}^{2}$ [controls]), average $\mathrm{HbA1c}(8.6 \%$ [cases] vs $6.3 \%$ [controls]) and average fasting glucose level (10.1 $\mathrm{mmol} / \mathrm{L}$ [cases] vs. $5.3 \mathrm{mmol} / \mathrm{L}$ [controls]) compared to controls. Similarly, a history of comorbidities and drug use was found to be higher among the cases than among the controls. A history of other GC use within 6 months before the index date was higher among the cases $(17.0 \%)$ as compared to the controls $(9.5 \%)$.

Current use of oral GCs was associated with an increased risk of receiving a first NIAD prescription (OR 2.63 [95\% CI 2.53-2.73]), Table 2. After adjusting for relevant confounders the corresponding adjusted (adj.) OR was 2.55 (95\% CI 2.432.68). The risk of first NIAD prescription decreased with increasing number of parenteral GC prescriptions compared to patients without oral GCs use; adj. OR was 3.38 (95\% CI 3.11-3.68) in group with 1-4 prescriptions, adj. OR 3.09 (95\% CI 2.72-3.52) in group with 5-7 prescriptions and adj. OR 2.04 (1.91-2.18) in the group with $>8$ prescriptions.

Table 3 shows an association between the use of parenteral GCs and receiving a first NIAD prescription, crude OR 1.29 [95\% CI 1.15-1.44]. However, after full statistical adjustment for confounders no association was found (OR 0.88 [95\% CI 0.76-1.02]). There was no difference in the effect on risk of first NIAD prescription with increasing number of parenteral GC prescriptions compared to patients without parenteral GC use. Furthermore, there was no difference between the different parenteral GC substances (Table 4).

\section{Discussion}

This study found no association between the use of parenterally administered GCs and the risk of receiving a first prescription of a NIAD as a proxy for new onset T2DM. An increase in the number of GC prescriptions or the type of parenteral GC was not associated with risk of new onset T2DM compared to no parenteral GC use. However, in line with other observational studies, we found an increased risk of GC-induced diabetes among oral GC users compared to nonusers $[1,6,3]$. This provides evidence for the 'assay sensitivity' of our data source, study design and definitions of exposure and outcome.

We did not find an association between the use of parenteral GCs and new onset of T2DM. First, this may be explained by the short duration and intermittent use of parenteral GCs. The effect of GCs is usually transient and reversible. As GC doses are reduced, their effect on endocrine metabolism returns to baseline and drug induced diabetes is expected to resolve [8]. Among oral GC users, a continuous GC scheme and long duration have been described as predictors for T2DM $[5,7]$. Blackburn et al. showed that the incidence of T2DM increase in time among oral GC users. The incidence of T2DM increased after $>3$ months of GC use among oral GC users compared with the reference group. The number needed to harm (NNH) for continuous use of oral GCs over 1,2 and 3 years were 41, 23 and 16 respectively [3]. In our study approximately $85 \%$ of the cases currently using a parenteral GC had 1-4 prescriptions prior to index date. When a parenteral GC was prescribed more than one time to a single patient, the average days between each prescription was 439 days. This intermittent use and short duration of parenteral GC use may be too short to affect the development of T2DM. Furthermore, the risk of new onset of T2DM within current GC users with $>8$ prescriptions was increased (OR 1.55 [95\% CI 0.70-3.43]). This effect, however, was not statistically significant, possibly due to a small sample size. Secondly, most of the parenteral GCs are locally administered. Of the parenteral GCs, methylprednisolone was mostly used in both cases and controls (about 65\%). In general, this GC is used intra-articularly or intramuscularly. A previous study showed that intra-articularly administered GCs increased glucose concentrations in patients with controlled diabetes [13]. However, compared to continuous use of oral GC, when using 


\begin{tabular}{|c|c|c|}
\hline Characteristic & $\begin{array}{l}\text { Controls } \mathrm{n}=(\%) \\
\mathrm{n}=177154\end{array}$ & $\begin{array}{l}\text { Cases } n=(\%) \\
n=177154\end{array}$ \\
\hline Mean age at index date (years, (SD)) & $60.8(15.0)$ & $60.8(15.0)$ \\
\hline Gender, females & $83,359(47.1)$ & $83,359(47.1)$ \\
\hline \multicolumn{3}{|l|}{ Smoking status } \\
\hline Never & $77,842(43.9)$ & $71,544(40.4)$ \\
\hline Current & $34,349(19.4)$ & $32,667(18.4)$ \\
\hline Ex & $45,412(25.6)$ & $64,476(36.4)$ \\
\hline Missing & $19,551(11.0)$ & $8467(4.8)$ \\
\hline BMI $\left(\mathrm{kg} / \mathrm{m}^{2}\right.$, mean, (SD)) & $26.5(4.9)$ & $31.4(6.6)$ \\
\hline \multicolumn{3}{|l|}{ By category } \\
\hline$<25.0 \mathrm{~kg} / \mathrm{m}^{2}$ & $58,027(32.8)$ & $22,597(12.8)$ \\
\hline $25-29.9 \mathrm{~kg} / \mathrm{m}^{2}$ & $54,671(30.9)$ & $53,338(30.1)$ \\
\hline $30-34.9 \mathrm{~kg} / \mathrm{m}^{2}$ & $20,258(11.4)$ & $46,940(26.5)$ \\
\hline$\geq 35.0 \mathrm{~kg} / \mathrm{m}^{2}$ & $7757(4.4)$ & $40,473(22.8)$ \\
\hline BMI missing & $36,441(20.6)$ & $13,806(7.8)$ \\
\hline \multicolumn{3}{|l|}{ HbA1c most recent within the year prior to index date } \\
\hline HbA1c (mean, (SD)) & $6.3(1.2)$ & $8.6(1.8)$ \\
\hline \multicolumn{3}{|l|}{ By category } \\
\hline$<6.5 \%$ & $2334(1.3)$ & $5138(2.9)$ \\
\hline $6.5-7.9 \%$ & $712(0.4)$ & $37,484(21.2)$ \\
\hline $8.0-9.4 \%$ & $216(0.1)$ & $27,313(15.4)$ \\
\hline$\geq 9.5$ & $86(0.0)$ & $24,119(13.6)$ \\
\hline HbA1c missing & $173,806(98.1)$ & $83,100(46.9)$ \\
\hline \multicolumn{3}{|c|}{ Fasting glucose most recent within the year prior to index date } \\
\hline Fasting glucose (mean, (SD)) & $5.3(0.8)$ & $10.1(4)$ \\
\hline \multicolumn{3}{|l|}{ By category } \\
\hline$<6.0 \mathrm{mmol} / \mathrm{L}$ & $8748(4.9)$ & $2075(1.2)$ \\
\hline $6.0-7.4 \mathrm{mmol} / \mathrm{L}$ & $1181(0.7)$ & $8329(4.7)$ \\
\hline $7.5-8.9 \mathrm{mmol} / \mathrm{L}$ & $98(0.1)$ & $9080(5.1)$ \\
\hline$\geq 9.0 \mathrm{mmol} / \mathrm{L}$ & $39(0.0)$ & $17,814(10.1)$ \\
\hline Fasting glucose missing & $167,088(94.3)$ & $139,856(78.9)$ \\
\hline \multicolumn{3}{|l|}{ History of comorbidity ever before index date } \\
\hline $\mathrm{T} 2 \mathrm{DM}$ & $1955(1.1)$ & $133,069(75.1)$ \\
\hline Retinopathy & $902(0.5)$ & $9161(5.2)$ \\
\hline Neuropathy & $1258(0.7)$ & $3528(2.0)$ \\
\hline Angina & $11,193(6.3)$ & $20,290(11.5)$ \\
\hline AMI & $6186(3.5)$ & $11,880(6.7)$ \\
\hline Heart failure & $4173(2.4)$ & $8528(4.8)$ \\
\hline Hypercholesterolemia & $9025(5.1)$ & $16,572(9.4)$ \\
\hline Hypertension & $44,686(25.2)$ & $82,665(46.7)$ \\
\hline Arrhythmia & $8403(4.7)$ & $12,919(7.3)$ \\
\hline Cerebrovascular disease & $8115(4.6)$ & $12,489(7.0)$ \\
\hline Osteoarthritis & $28,248(15.9)$ & $35,440(20.0)$ \\
\hline Rheumatoid arthritis & 2549 (1.4) & 2919 (1.6) \\
\hline Transplantation & $210(0.1)$ & $412(0.2)$ \\
\hline \multicolumn{3}{|l|}{ History of drug use within 6 months before index date } \\
\hline Loop diuretics & $9178(5.2)$ & $21,481(12.1)$ \\
\hline Calcium channel blockers & $19,204(10.8)$ & $38,179(21.6)$ \\
\hline Beta-blockers & $17,922(10.1)$ & $35,116(19.8)$ \\
\hline RAAS inhibitors & $25,596(14.4)$ & $65,994(37.3)$ \\
\hline Statins & $25,241(14.2)$ & $76,753(43.3)$ \\
\hline Antipsychotics & $2404(1.4)$ & $4367(2.5)$ \\
\hline Use of other glucocorticoids (oral, dermal, nasal etc.) & $16,787(9.5)$ & $30,073(17.0)$ \\
\hline
\end{tabular}

Abbreviations: SD = standard deviation, BMI = body mass index, HbA1c = Glycated Haemoglobin, AMI = acute myocardial infarction, $\mathrm{T} 2 \mathrm{DM}=$ Type 2 Diabetes Mellitus, T1DM = Type 1 Diabetes Mellitus, RAAS = renin-angiotensin-aldosterone-system. 
Table 2 - Use of oral GCs and risk of first NIAD prescription.

\begin{tabular}{|c|c|c|c|c|c|c|}
\hline Oral GC use & Controls $(n=177154)$ & Cases $(n=177154)$ & Crude OR & (95\%CI) & Adjusted $\mathrm{OR}^{\mathrm{a}}$ & $(95 \% \mathrm{CI})$ \\
\hline Never & 156,679 & 146,700 & Reference & & Reference & \\
\hline Past & 15,104 & 18,988 & 1.37 & $(1.34-1.40)$ & 1.04 & $(1.01-1.07)$ \\
\hline Recent & 1426 & 1946 & 1.48 & $(1.38-1.59)$ & 1.14 & $(1.04-1.25)$ \\
\hline Current & 3945 & 9520 & 2.63 & $(2.53-2.73)$ & 2.55 & $(2.43-2.68)$ \\
\hline \multicolumn{7}{|c|}{ By no of prescriptions ever before index date } \\
\hline $1-4$ & 1162 & 3438 & 3.23 & $(3.02-3.45)$ & 3.38 & $(3.11-3.68)$ \\
\hline $5-8$ & 492 & 1421 & 3.15 & (2.84-3.49) & 3.09 & $(2.72-3.52)$ \\
\hline$>8$ & 2291 & 4661 & 2.22 & $(2.11-2.33)$ & 2.04 & $(1.91-2.18)$ \\
\hline \multicolumn{7}{|c|}{ By type of GC, most recent prior to index date } \\
\hline Triamcinolone & 0 & 0 & - & - & - & - \\
\hline Prednisolone & 3640 & 8426 & 2.52 & $(2.43-2.63)$ & 2.33 & $(2.22-2.46)$ \\
\hline Methylprednisolone & 4 & 6 & 1.70 & $(0.47-6.12)$ & 4.37 & $(0.68-28.17)$ \\
\hline Hydrocortisone & 81 & 206 & 2.69 & $(2.08-3.48)$ & 2.41 & $(1.73-3.35)$ \\
\hline Dexamethasone & 94 & 738 & 8.49 & $(6.85-10.53)$ & 15.16 & $(11.80-19.47)$ \\
\hline Betamethasone & 17 & 28 & 1.77 & $(0.97-3.24)$ & 1.56 & $(0.71-3.42)$ \\
\hline Cortisone & 5 & 6 & 1.24 & $(0.38-4.05)$ & 1.00 & $(0.26-3.79)$ \\
\hline Fludrocortisone & 104 & 110 & 1.15 & $(0.88-4.50)$ & 1.48 & $(1.05-2.10)$ \\
\hline
\end{tabular}

Abbreviations: $\mathrm{GCs}=$ glucocorticosteroids, $\mathrm{BMI}=$ body mass index, RAAS $=$ renin-angiotensin-aldosterone-system, $\mathrm{OR}=$ odds ratio, $\mathrm{CI}=$ confidence interval.

a Adjusted for: BMI and smoking status. History of disease ever before index date: angina, heart failure, hypertension, neuropathy, osteoarthritis. Drug use in 6 months prior to index date: loop diuretics, RAAS-inhibitors, statins, calcium channel blockers.

Table $\mathbf{3}$ - Use of parenteral GCs and risk of first NIAD prescription by number of parenteral GC prescriptions.
\begin{tabular}{lllllll} 
GC use & Controls $(\mathrm{n}=177154)$ & Cases $(\mathrm{n}=177154)$ & Crude OR & $(95 \%$ CI $)$ & Adjusted OR & $(95 \%$ CI $)$ \\
\hline Never & 167,423 & 164,615 & Reference & & Reference & \\
Past & 8656 & 11,191 & 1.34 & $(1.30-1.38)$ & 1.02 & $(0.98-1.06)$ \\
Recent & 503 & 639 & 1.32 & $(1.18-1.49)$ & 0.91 & $(0.77-1.06)$ \\
Current & 572 & 709 & 1.29 & $(1.15-1.44)$ & 0.88 & $(0.76-1.02)$ \\
By no of prescriptions ever before index date & 601 & & & $(1.09-1.38)$ & 0.87 & $(0.74-1.03)$ \\
$1-4$ & 507 & 76 & 1.23 & $(1.20-2.50)$ & 0.76 & $(0.48-1.23)$ \\
$5-8$ & 46 & 32 & 1.73 & $(0.99-3.10)$ & 1.55 & $(0.70-3.43)$ \\
\hline$>8$ & 19 & 1.76 & & \\
\hline
\end{tabular}

Abbreviations: NIAD = Non-insulin antidiabetic drug, GCs = Glucocorticosteroids, BMI = body mass index, RAAS = renin-angiotensin-aldosterone-system, $\mathrm{OR}=$ odds ratio, $\mathrm{CI}=$ confidence interval.

a Adjusted for: BMI and smoking status. History of disease ever before index date: angina, heart failure, hypertension, neuropathy, osteoarthritis. Drug use in 6 months prior to index date: loop diuretics, RAAS-inhibitors, statins, calcium channel blockers, other glucocorticoids.

\section{Table 4 - Use of parenteral GCs and risk of first NIAD prescription by substance of parenteral GC.}

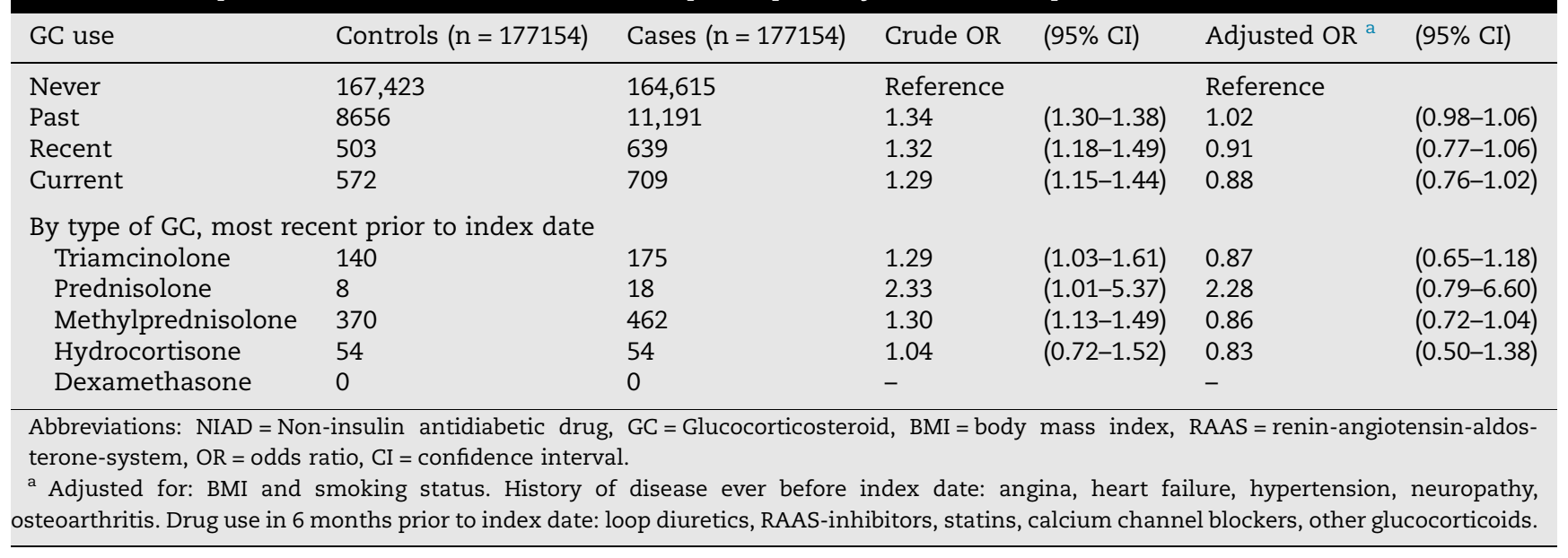


GCs locally the time exposed to sufficiently high concentrations may be too short to have systemic effects and to develop T2DM. After administration of methylprednisolone intraarticularly, peak levels were observed after 2-12 $\mathrm{h}$ and complete clearance from the blood after 5 days.[18-20] After oral administration of methylprednisolone, peak concentrations were observed after $1.5 \mathrm{~h}$ and its elimination half-life is 1.8 h [21].

Our study has several strengths and limitations. To our knowledge, this is the first study that evaluated the association between use of parenteral GCs and new onset of T2DM. It was conducted using the world's largest primary care database which is representative for $6.9 \%$ of the British population. This enabled us to assess the risk of T2DM in 12,539 users of parenteral GCs. Third, we have evaluated the effect of duration of parenteral GC use and risk of T2DM by stratifying our analyses by number of prescriptions.

A limitation of this study is that the causal interpretation of the findings will be restricted. Although we corrected for relevant covariates, confounding remains a considerable concern in observational studies. Due to limited availability of data we were unable to control for some factors, such as ethnicity, and genetic factors. This may influence the results, since ethnicity and genetic factors are important risk factors for developing T2DM [8]. In the United Kingdom, South Asian and Black communities are two to four times more likely to develop T2DM than those with a Caucasian background $[22,23]$ Since the majority of British population includes Caucasians [24], ethnicity is not likely to be an important limitation in our study. We did not stratify by gender as this has not been described as a risk factor for glucocorticoid induced diabetes mellitus [8].

Confounding by indication may be another concern in observational studies. GCs are mostly prescribed in patients with rheumatoid arthritis, systemic lupus erythematosus and other inflammatory disease. These patients are at increased risk of developing cardiovascular disease and T2DM because of their pathological background. Based on this knowledge, GC users are, due to their co-morbidity, more likely to develop T2DM [25]. However, these factors did not change the beta-coefficient of current GC use with $>5 \%$ compared to the crude analysis. Therefore, they were not included as relevant confounders. Furthermore, patients with inflammatory diseases may have higher endogenous GC levels caused by disease-related stress, which may increase serum glucose levels. As this is possibly present in the cases, this may also lead to confounding by indication.

Misclassification of exposure may also be of concern. Prescription data were used to determine exposure. However, the nature of this data does not allow us to confirm compliance of medication. Furthermore, since CPRD database does not contain prescription data from hospitals or day care clinics, we were not able to include parenteral GC administrations in hospitals in our analysis. These factors may have led to underestimation of the exposure. However, since most locally used parenteral GCs are administered by nurses or GPs in the primary care setting, this is unlikely to have influenced the results. A dose-response relationship could not be accurately ascertained given the limitations in data availability regarding the different routes of administration and different dose regimes of parenteral GCs. A first NIAD prescription could be considered to be an inadequate definition of new onset of T2DM. The earlier stages of T2DM are usually either undetected or treated with non-pharmacological methods. Therefore, at the time of first prescription the disease has likely been present for some time may therefore be of concern. However, a first NIAD prescription provides a clear date at which a stage of the disease is reached that requires pharmacological treatment. Fasting glucose or HbA1c levels do not provide such a clear and unambiguous cut-off. Furthermore, NIAD use has been previously used in CPRD studies to define T2DM [26,27]. Since antidiabetics are taken exclusively to treat diabetes, the possibility of misclassifying non-diseased subjects as diseased subjects is minimal. Finally, we were not able to determine the effect of intravenous use of GCs on T2DM. Since intravenous GCs are administered in hospitals and hospital data is limited in the CPRD database [28], we only focused on locally (intraarticular/intrabursal/periarti cular/intramuscular/intradermal) used parenteral GCs in the primary care line setting.

In conclusion, this case-control study does not demonstrate a statically significant increase in the risk for new onset of T2DM among current users of parenteral GCs compared to non-users. This is in contrast to our findings demonstrating an association between oral GC use and the risk of T2DM. Since this was the first observational study assessing the effects of parenteral use of GCs on onset of TD2M, more studies are necessary to confirm the absence of possible metabolic side effects of parenteral GCs.

\section{Conflicts of interest}

JN, AK, PS, BvdB and FV: None

\section{Acknowledgement}

None.

\section{Appendix A. Supplementary material}

Supplementary data associated with this article can be found, in the online version, at https://doi.org/10.1016/j.diabres.2018. 02.010 .

\section{R E F E R E N C E S}

[1] Gulliford MC, Charlton J, Latinovic R. Risk of diabetes associated with prescribed glucocorticoids in a large population. Diabetes Care 2006;29:2728-9.

[2] Clore JN, Thurby-Hay L. Glucocorticoid-induced hyperglycemia. Endocr Pract 2009;15:469-74.

[3] Blackburn D, Hux J, Mamdani M. Quantification of the risk of corticosteroid-induced diabetes mellitus among the elderly. J Gen Intern Med 2002;17:717-20.

[4] Trence DL. Management of patients on chronic glucocorticoid therapy: an endocrine perspective. Prim Care 2003;30:593-605.

[5] Tamez-Pérez HE, Quintanilla-Flores DL, Rodríguez-Gutiérrez R, González-González JG, Tamez-Peña AL. Steroid 
hyperglycemia: prevalence, early detection and therapeutic recommendations: a narrative review. World J Diabetes 2015 Jul 25;6(8):1073-81.

[6] Gurwitz JH, Bohn RL, Glynn RJ, Monane M, Mogun H, Avorn J. Glucocorticoids and the risk for initiation of hypoglycemic therapy. Arch Intern Med 1994 Jan 10;154(1):97-101.

[7] Katsuyama T, Sada KE, Namba S, Watanabe H, Katsuyama E, Yamanari T, et al. Risk factors for the development of glucocorticoid-induced diabetes mellitus. Diabetes Res Clin Pract 2015 May;108(2):273-9.

[8] Suh Sunghwan, Park Mi Kyoung. Glucocorticoid-induced diabetes mellitus: an important but overlooked problem. Endocrinol Metab 2017 Jun;32(2):180-9.

[9] Rafacho A, Ortsäter H, Nadal A, Quesada I. Glucocorticoid treatment and endocrine pancreas function: implications for glucose homeostasis, insulin resistance and diabetes. J Endocrinol 2014;223(3):R49-62.

[10] Pasieka AM, Rafacho A. Impact of glucocorticoid excess on glucose tolerance: clinical and preclinical evidence. Metabolites 2016;6(3). Aug 3.

[11] Berger A, Bozic K, Stacey B, Edelsberg J, Sadosky A, Oster G. Patterns of pharmacotherapy and health care utilization and costs prior to total hip or total knee replacement in patients with osteoarthritis. Arthritis Rheum 2011 Aug;63(8):2268-75.

[12] Tamez Perez HE, Gómez de Ossio MD, Quintanilla Flores DL, Hernández Coria MI, Tamez Peña AL, Cuz Pérez GJ, et al. Glucose disturbances in non-diabetic patients receiving acute treatment with methylprednisolone pulses. Rev Assoc Med Bras 2012;58(1):125-8. Jan-Feb.

[13] Habib GS, Bashir M, Jabbour A. Increased blood glucose levels following intra-articular injection of methylprednisolone acetate in patients with controlled diabetes and symptomatic osteoarthritis of the knee. Ann Rheum Dis 2008;67(12):1790-1.

[14] Habib G, Safia A. The effect of intra-articular injection of betamethasone acetate/betamethasone sodium phosphate on blood glucose levels in controlled diabetic patients with symptomatic osteoarthritis of the knee. Clin Rheumatol 2009;28(1):85-7.

[15] Younes M, Neffati F, Touzi M, Hassen-Zrour S, Fendri Y, Béjia I, et al. Systemic effects of epidural and intra-articular glucocorticoid injections in diabetic and non-diabetic patients. Joint Bone Spine 2007;74(5):472-6.

[16] Herrett E, Gallagher AM, Bhaskaran K, Forbes H, Mathur R, van Staa T, et al. Data resource profile: clinical practice research datalink (CPRD). Int J Epidemiol 2015;44(3):827-36.
[17] Luna B, Feinglos MD. Drug-induced hyperglycemia. JAMA 2001;286(16):1945-8.

[18] Armstrong RD, English J, Gibson T, Chakraborty J, Marks V. Serum methylprednisolone levels following intra-articular injection of methylprednisolone acetate. Ann Rheum Dis 1981;40(6):571-4.

[19] Reeback JS, Chakraborty J, English J, Gibson T, Marks V. Plasma steroid levels after intra-articular injection of prednisolone acetate in patients with rheumatoid arthritis. Ann Rheum Dis 1980;39(1):22-4.

[20] Habib GS. Systemic effects of intra-articular corticosteroids. Clin Rheumatol 2009;28(7):749-56.

[21] Sayed M, Al-Habet H, Rogers HJ. Methylprednisolone pharmacokinetics after intravenous and oral administration. Br J Clin Pharmac 1989;27:285-90.

[22] Health and social care information centre. Health Survey for England 2004, Health of Ethnic Minorities; 2006.

[23] Tillin T, Hughes AD, Godsland IF, Whincup P, Forouhi NG, Welsh $\mathrm{P}$, et al. Insulin resistance and truncal obesity as important determinants of the greater incidence of diabetes in Indian Asians and African Caribbeans compared with Europeans. The Southall and Brent revisited (SABRE) cohort. Diabetes Care 2012;36(2):383-93.

[24] Wikipedia (2016). Demography of United Kingdom. Retrieved August 23, 2016. https://en.wikipedia.org/wiki/Demography_ of_the_United_Kingdom/.

[25] Han C, Robinson Jr DW, Hackett MV, Paramore LC, Fraeman $\mathrm{KH}$, Bala MV. Cardiovascular disease and risk factors in patients with rheumatoid arthritis, psoriatic arthritis, and ankylosing spondylitis. J Rheumatol 2006;33(11):2167-72.

[26] Wijnands JM, van Durme CM, Driessen JH, Boonen A, Klop C, Leufkens B, et al. Individuals with type 2 diabetes mellitus are at an increased risk of gout but this is not due to diabetes: a population-based cohort study medicine (Baltimore). 2015;94 (32):e1358.

[27] Peeters PJ, Bazelier MT, Leufkens HG, de Vries F, De Bruin ML. The risk of colorectal cancer in patients with type 2 diabetes: associations with treatment stage and obesity. Diabetes Care 2015;38(3):495-502.

[28] Bazelier MT, van Staa T, Uitdehaag BMJ, Cooper C, Verstergaard P, Bentzen J, et al. The risk of fracture in patients with multiple sclerosis: the UK general practice research database. J Bone Miner Res 2011;26(9):2271-9. 